Doi: 10.1016/j.cie.2014.07.029

\title{
A FRAMEWORK FOR SUSTAINABLE PERFORMANCE ASSESSMENT OF SUPPLY CHAIN MANAGEMENT PRACTICES
}

\author{
Emilie CHARDINE-BAUMANN ${ }^{(a)}$, Valérie BOTTA-GENOULAZ ${ }^{(b, 1)}$ \\ (a,b) Université de Lyon, France
}

(a,b) Université de Lyon, INSA-Lyon, DISP EA 4570, F-69621 Villeurbanne Cedex, France

(a) tel. +33 6582259 39, emiliebaumann@hotmail.com

(b) tel. +334724360 74, valerie.botta@insa-lyon.fr

\begin{abstract}
The introduction of the concept of sustainable development in supply chain management has been identified not only as a constraint but also as a way to improve performance, impacting the competitiveness of a company and of its supply chain organization. To evaluate and analyze the potential relationships between traditional supply chain management practices and their impact on performance, we propose a framework for sustainable performance characterization and an analytical model for sustainable performance assessment. The framework is used to characterize a company's sustainable performance in the economic, environmental and social fields. The analytical assessment model, based on the relationships between a supply chain management practice and the three fields of sustainable development, serves to produce the sustainable performance profile of a practice, identified by a triad. An application of this profile to two well-known best practices of supply chain management allows us to identify their performance from a sustainable development point of view. Practitioners can easily use the proposed framework for highlighting SCM practices that impact sustainable performance more positively, depending on their objectives.
\end{abstract}

Keywords: Supply chain management, Sustainability, Performance evaluation, Sustainable development, Assessment method, management practices.

\section{Introduction}

Sustainable development is defined in the Brundtland Report of the World Commission on Environment and Development (WCED, 1987) as "development that meets the needs of the present without compromising the ability of future generations to meet their own needs”. This concept plays an important role in businesses and supply chains of the 21st century. Supply Chain Management (SCM) is defined as the management of exchanges of materials and information in the logistics process stretching from the

1 Corresponding author: Prof. V. Botta-Genoulaz, INSA-Lyon, DISP EA 4570, bât Léonard de Vinci, 21 avenue Jean Capelle, F-69621 Villeurbanne Cedex, France, tel. +33 4724360 74, fax +33 4724383 14, valerie.botta@insa-lyon.fr 
Doi: 10.1016/j.cie.2014.07.029

purchasing of raw materials to the delivery of end-products to end customers, so linking several firms (Cooper, Lambert \& Pagh, 1997). SCM is thus responsible for material flows within human society as well as the exchange of material and energy with the environment. The impacts of SCM should be determined in relation to the three main aspects of sustainability: environmental performance, social responsibility and economic contribution. Yet the focus today is mainly on the economic dimension, through the evaluation of some well-known or best practices. The APQC ${ }^{2}$ defines a best practice as: "Any practice or experience which has proved its value or which is used in an efficient way in an organization, and can be applied in other organizations".

We retain that:

- A best practice is formalized. Its formalization often takes the shape of an index card. This index card is structured in three parts: the problem is meticulously described; then the solution to this problem is detailed by the individual; and finally the results are indicated as evidence that it is an effective practice and should therefore be reused (Perrin, 2006).

- It is effective. Its effectiveness has to meet all the criteria of the performance assessment of a process: relevance, coherence, effectiveness, efficiency, robustness and sustainability (Maire, Bronet \& Pillet, 2005).

- It is reusable. Although attached to a context, a best practice is supposed to be reproduced faithfully or, more usually, adapted to another context. “A best practice could be adapted to another situation” $\left(\mathrm{KIT}^{3}\right)$.

The concept of sustainable performance was introduced subsequent to that of sustainable development. We define the sustainable performance of a practice as the combination of its economic, social and environmental performances (see Figure 1). This corresponds to a holistic conception designed to indicate an integration of the performances in a synthetic approach. Such integration can imply coherence between the three dimensions with causality models connecting various factors stemming from different dimensions.

The aim of this paper is to verify the qualification of "best" for SCM practices in the three dimensions of sustainability. Is a best practice from the economic point of view also "the best" from the environmental and social points of view?

\footnotetext{
2 American Productivity and Quality Council (APQC). Available on www.apqc.org.

3 Royal Tropical Institut (KIT). Available on www.kit.nl
} 
Doi: 10.1016/j.cie.2014.07.029

To answer this question, we first define sustainable performance, which then allows us to suggest an analytical model for the assessment of SCM practices.

--- Insert Figure 1 here ---

The remainder of the paper is organized into five sections. A literature review on assessment of SCM practices and on sustainable performance assessment is presented in Section 2. In Section 3 we propose the model to characterize sustainable performance. This lays the foundation for Section 4, which introduces the analytical assessment model. In Section 5 an application is provided to illustrate how the framework can work in practice. The paper concludes with a brief summary and implications for future research, and suggests some managerial insights.

\section{Literature review}

The concept of sustainable performance is a recent research theme and its assessment is even more recent. In this section we propose a literature review with two focuses: tools to assess SCM practices and tools to assess sustainability.

\subsection{Tools to assess SCM practices}

There are many tools to assess SCM practices; in this review we concentrate on assessment audits. We have identified four international tools for auditing a supply chain: Odette EVALOG, Efficient Consumer Response, the Oliver Wight Class A Checklist, and the SCOR model. None of them are really imperative on the market.

The Odette EVALOG standard is the result of the collaborative effort of Odette International Limited and the Automotive Industry Action Group, and is based on the Odette Logistics Evaluation (OLE) and the Materials Management Operations Guidelines (MMOG), respectively used in Europe and North America. The aim of these two organizations was to produce the Global Material Management Operations Guidelines - Logistics Evaluation -, a set of global guidelines for materials processes, designed to reduce the workload for suppliers and customers. The Odette EVALOG standard, published in 1999 (Galia, 2007) to provide firms with a common assessment tool for their supply chain, is widely used in Europe.

Although it was designed and developed for the automobile industry, it has also been used in others industries. It analyzes six fields: four of them concern processes - customer relations, supplier relations, production, and product development -, and the other two are research topics: corporate strategy and corporate structure. The standard is used to assess about sixty best practices. The revised evaluation score 
Doi: 10.1016/j.cie.2014.07.029

sheet places suppliers in an "A", "B", or "C" classification based on the organization's compliance with the guidelines.

Specific to the retail sector, the Efficient Consumer Response (ECR, 2008) is a tool composed of a set of best practices in sustainable transport. This SCM performance assessment tool enables companies of any size to self-assess against a reference list. It is composed of thirteen best practices on loading, deliveries, drivers' involvement, technologies, and the business network. These practices are assessed on five levels, from the most basic to excellence. Once the evaluation has been completed, answers are reflected in a network plan highlighting those areas on which the company must concentrate.

Oliver Wight has developed the Class A Checklist for Business Excellence (Oliver Wight International Inc., 2005), a tool designed to assess processes and practices which enable excellence to be attained throughout the company. The processes concerned are: Strategic Planning, Managing and Leading People, Driving Business Improvement and Integrated Business Management, Products \& Services, Demand, Supply Chain, Internal Supply and External Sourcing. Each practice is audited on a four-level scale, from 0 - Nothing de facto (this practice is necessary but not begun yet) to 4 - Excellent (this practice is perfectly mastered; results are of the highest expected level).

The SCOR (Supply Chain Operations Reference) model was created in 1996 by the Supply Chain Council (SCC, 2000) as a standard framework for companies. It defines a method, reference processes, key indicators and best practices to represent, assess and diagnose the supply chain. The SCOR model proposes five families of metrics for assessing SCM practices: reliability, responsiveness, flexibility, costs, and asset management. The eighth version of the SCOR model (SCC, 2008) also includes the GREENSCOR. This added module underlines some best practices like "implementation of an Environmental Management System”, “development of partnerships with suppliers”, “identifying green materials”, “maximization loadings”, and so on. The best practices are linked to sustainable development and five environmental indicators: carbon emissions, air pollutant emissions, liquid waste generated, solid waste generated and percentage of recycled waste. The SCOR model is unquestionably the main world reference for supply chain assessment, as the 800 or so participating companies attest. It serves as a reference point to estimate how the supply chain is positioned, how it is structured and what type of functioning it adopts.

\subsection{The sustainability in performance assessment standards}

Several new standards and scientific contributions have been published recently to help companies assess their sustainable performance. We note that commitment standards, such as the Global Compact (United 
Doi: 10.1016/j.cie.2014.07.029

Nations Environment Program, 2000), propose some key principles but no assessment method, and that certification standards are regrettably highly specialized. In fact, SA8000 (SAI, 2008) is specialized in the social dimension and seldom applicable to companies, whereas EMAS (European Commission, 2009) proposes an assessment tool for the environmental dimension only. Note that ISO 26000 (ISO, 2010) does propose an assessment framework for environmental and social performance, which is applicable to companies, and the reporting standard GRI (GRI, 2007), designed for companies, integrates three dimensions of sustainable performance. However, these two standards do not encompass all the fields of sustainable development, and are therefore not exhaustive.

Concerning scientific contributions in the literature, the first conceptual models (Carroll, 1979; Clarkson, 1995; Wood, 1991) clarified the concept of social responsibility by showing its origins and its first assessment criteria. More recent conceptual models characterize sustainable performance and identify the major fields to consider in its assessment. In particular, these include the models of Castka and Balzarova (2008), Jash (2000), Krajnc and Glavic (2003), Rubio and Corominas (2008), Tseng, Divinagracia and Divinagracia (2009) and Veleva, Hart, Greiner and Crumbley (2001). Case studies deal essentially with the implementation of green practices in supply chains, their motivation and their degree of implementation (Côté et al., 2008; Ferretti, Zanoni, \& Zavanella, 2007; Lambert, Riopel \& Abdul-Kader, 2011; Vachon \& Klassen, 2008). But to date, no one has assessed impacts of SCM practices on the sustainable performance of companies.

In mathematical models, most of the contributions are concentrated on one dimension: the economic dimension. Two approaches have held our attention and influenced our work: multi-criteria approaches and composite sustainable indexes. Until now, multi-criteria approaches integrating at least two sustainable dimensions have been rare (Cruz \& Wakolbinger, 2008; Sawadogo \& Anciaux, 2010; Zhou, Cheng \& Hua, 2000), and none have dealt with all three dimensions. The second approach concerns the aggregation of sustainable indicators in a composite index. This approach by levels is interesting but the actual models in Krajnc and Glavic (2005), Singh, Murty, Gupta and Dikshit (2007), Siracusa, La Rosa and Sterlini (2004) and Jung, Kim and Rhee (2001) authorize compensations between dimensions, which, from our point of view, do not seem to be consistent with the concept of sustainable development.

\subsection{Needs for framework for sustainable performance assessment of SCM practices}

Although some leading international organizations propose tools to audit SCM practices, few of them have matured towards the assessment of sustainability. The most sustainability-oriented tool is the SCOR model with the introduction of the GREENSCOR added model. However it does not integrate the three 
Doi: 10.1016/j.cie.2014.07.029

dimensions of sustainable development simultaneously. Indeed, to date there is no standardized tool allowing companies to assess the sustainable performance of SCM practices.

Moreover, with the growing interest in sustainable development, new tools are appearing. These tools introduce sustainability but none of them proposes a homogenous assessment of all three dimensions, and none is applicable to supply chain management as a whole.

Thus, even though sustainable performance assessment in SCM is increasing, there is insufficient integration and maturity in this respect in the socioeconomic sphere. This paper seeks to fill this gap by providing a framework for sustainable performance assessment of SCM practices. The framework introduces and reinforces the notion of simultaneous assessment of the three sustainable dimensions.

\section{A characterization model of sustainable performance}

The three dimensions of the sustainable development triptych are: environmental performance, social responsibility, and economic contribution. We have built a model which can be used to assess the sustainable performance of a SCM practice in each of these dimensions, broken down more specifically into fields and sub-fields. The "fields" correspond to the main challenges of each dimension, while the "sub-fields" are subsets of these big challenges in the socioeconomic sphere - not to be confused with indicators which measure impacts on the sub-fields.

Because it is common in the literature on economic performance evaluation to cover five fields (reliability, responsiveness, flexibility, finance and quality), and in order to preserve the balance between the three dimensions of the sustainable development concept, we suggest a model composed of fifteen sustainable fields, five for each dimension. Each field is then broken down into several sustainable subfields, adapted to the sphere of supply chain management. The number of sub-fields per field is not homogeneous because we allow for compensations between sub-fields. The aim is for a company to be able to position itself in at least one sub-field of a given field.

Moreover, we have based our classification on two requirements recommended by Roy (1996):

- Exhaustiveness: it should not have too few fields; otherwise, some elements of assessment will not have been taken into account.

- Non-redundancy: Fields should not be duplicated; there should not be more of them than necessary.

The proposed characterization model of sustainable performance is therefore based on fifteen fields and sixty-seven sub-fields (see Table 1), all of which are drawn from the literature. The fields and sub-fields of each dimension are detailed in the following sub-sections. 
Doi: 10.1016/j.cie.2014.07.029

\subsection{Economic fields and sub-fields}

It is common in the literature on economic performance evaluation (SCC, 2008; Vachon \& Klassen, 2008) to cover five fields: reliability, responsiveness, flexibility, finance and quality.

Gunasekaran, Patel and Tirtiroglu (2001), Lynch and Cross (1991), SCC (2008), and Zhu, Sarkis and Lai (2007) present reliability in particular through four sub-fields. In fact, the impacts of a SCM practice would be evaluated on the basis of customer services (choice/range of products/services), suppliers’ service, reliability of stocks - particularly on out of stock -, and reliability of forecasts.

To evaluate responsiveness, we have borrowed eight sub-fields from Lynch and Cross (1991), SCC (2008) and Vachon and Klassen (2008):

- Design responsiveness, to evaluate the impacts of a practice on design responsiveness and product/service development.

- Purchase responsiveness, to evaluate the impacts of a practice on purchase responsiveness with regard to raw materials/components.

- Source responsiveness, to evaluate the impacts of a practice on source responsiveness with regard to raw materials/components.

- Production responsiveness, to evaluate the impacts of a practice on production responsiveness with regard to products/services.

- Delivery responsiveness.

- Sales responsiveness.

- Return responsiveness.

- Supply chain responsiveness.

Flexibility has been analyzed in particular by SCC (2008). We retain four sub-fields to evaluate the impacts of practice on suppliers, supply, production, and delivery flexibility.

The fourth field is "finance". Finance is a broad term which has already very often been analyzed. We have learned from the literature (GRI, 2007; Krajnc \& Glavic, 2005; Matos \& Hall, 2007; SCC, 2008) that financial performance of a SCM practice can be measured by its impact on the design costs of products/services, the purchase costs of raw materials/components, the source costs of raw materials/components, the production costs of products/services, the delivery costs, the return costs and the supply chain costs. 
Doi: 10.1016/j.cie.2014.07.029

"Evaluation of quality" is a field which is less common in terms of performance. We find some information in Matos and Hall (2007), in SCOR (SCC, 2008), and in Vachon and Klassen (2008). We define the impacts of quality in three sub-fields:

- Product/service quality, in order to estimate the impact of the practice on the ability of products/services to meet consumer expectations.

- Quality performance of suppliers, in order to estimate the impact of the practice on the capacity of suppliers to meet their customers' expectations.

- Production quality, in order to estimate the impact of the practice on the quality of services provided or on manufactured goods.

In order to preserve the balance between the three dimensions of the sustainable development concept, and to identify the five fields of each of the other two dimensions, we have carried out a significant review of the scientific literature, based on the following keywords: performance, sustainability supply chain, social responsibility performance, and reverse logistics.

\subsection{Environmental fields and sub-fields}

The characterization of the environmental fields and sub-fields allows us to estimate environmental impacts. We choose to define an environmental impact as a modification of the environment due to human intervention which may be actual or supposed (using resources or dumping waste in the environment), direct or indirect (case of industrial accidents for example), and which has a potentially harmful effect (from a simple nuisance to destruction) on the sustainability of the natural environment and ecosystems and consequently, a priori on human health. It is evident that the decisions and activities of companies inevitably have an impact on the natural environment, wherever they are implemented. These impacts may be related to the company's use of organic or other resources, to its production of pollution and waste, and to its other activities, its products and/or its services. To reduce these impacts, it is therefore advisable that companies adopt an integrated approach which takes into account the broader implications of their decisions and their activities from an economic, environmental and social point of view. An analysis of the inventory of the environmental fields found in the abundant literature on the subject, allows us to isolate five environmental fields: environmental management, the use of resources, pollution, dangerousness, and the natural environment.

Stemming from this analysis, Azapagic and Perdan (2000), Darnall, Jolley and Handfield (2006), and Jash (2000) and Warhurst (2002) define four sub-fields for evaluating the impacts of a SCM practice on environmental management: 
Doi: 10.1016/j.cie.2014.07.029

- Environmental budget, to evaluate the impacts of a practice on the amount of investment in environmental protection.

- Environmental certification, to evaluate the impacts of a practice on the number of certifications linked to environmental protection.

- Environmental compliance, to evaluate the impacts of practice on compliance with environmental regulations usually, and in particular if the industry is specific and regulated, for example the motor industry or the electrical appliances industry.

- Workers' implications in environmental protection, to evaluate the impacts of practice on the number of workers involved in environmental protection.

Azapagic and Perdan (2000), Jash (2000), Krajnc and Glavic (2003, 2005), Gauthier (2005), Michelsen, Magerholm, Fet and Dahlsrud (2006), Rao, O'Castillo, Intal Jr and Sajid (2006), and De Benedetto and Klemes (2009) complete the propositions of GRI (2007) and allow us to define five sub-fields linked to the use of resources:

- Renewable energy, to evaluate the impacts of a practice on renewable energy consumption (fossil and non-fossil sources).

- Recycled water, to evaluate the impacts of a practice on the recycling of used water.

- Inputs stemming from recycling, to evaluate the impacts of a practice on input consumption (raw material, packaging, consumables, etc.) stemming from recycling.

- Recyclable outputs, to evaluate the impacts of a practice on recyclable output production (products, packaging, etc.).

- Recyclable waste, to evaluate the impacts of a practice on the recycling of waste production (product or packaging rubbishes, etc.) stemming from the production cycle.

The third field "Pollution" has mainly been covered by GRI (2007) and SCC (2008), and has been completed by Barbiroli and Raggi (2003), De Benedetto and Klemes (2009), Jash (2000), Krajnc and Glavic (2003, 2005), Matos and Hall (2007), Noci (1997), Tam, Tam and Tsui (2004), and Zhu, Sarkis and Lai (2007). We propose to divide this field into four sub-fields:

- Air pollution. This sub-field allows us to evaluate the impacts of a practice on air pollution, in particular on CO2, NOx, SOx, lead, mercury and volatile organic compound emissions.

- Water pollution, to evaluate the impacts of a practice on water pollution, in particular on direct spillages in surface waters, whether deliberate or not, on involuntary streaming in surface waters, and on infiltrations in ground water. 
Doi: 10.1016/j.cie.2014.07.029

- Land pollution, to evaluate the impacts of a practice on soil pollution, in particular discharges of heavy metals, hydrocarbons, dioxins and phenols.

- Other pollution, to evaluate the impacts of a practice on other types of pollution, in particular noise, smells, visual pollution, vibrations and radiations.

Dangerousness has been analyzed by very few authors but in order to be as exhaustive as possible, we have included it in our model. Dangerousness has been analyzed by Barbiroli and Raggi (2003), Krajnc and Glavic (2005), Zhu and Sarkis (2004) and Zhu, Sarkis and Lai (2007). Based on these contributions, we propose to evaluate the impacts of a SCM practice on dangerousness, in three sub-fields:

- Dangerous inputs, to evaluate the impact of a practice on dangerous inputs like raw materials, packaging, consumables, etc.

- Dangerous outputs, to evaluate the impact of a practice on dangerous outputs like finished products, packaging, etc.

- Dangerous waste, to evaluate the impact of a practice on dangerous waste like rubbishes, etc.

The last field "Natural environment" is a term which includes:

- Eco-systemic services, to evaluate the impacts of a practice on eco-systemic services that contribute to well-being: food supply, water, fuel, etc. The purpose is to promote, protect and rehabilitate them.

- Respect for biodiversity, to evaluate the impacts of a practice on all forms and combinations of life, at all levels. This includes intra- and inter-species diversity, as well as ecosystem diversity. The protection of biodiversity is intended to ensure the survival of land and aquatic species, genetic variability and natural ecosystems.

- Land use, to evaluate the impacts of a practice on land use and on the sustainability of natural resources.

- Development of urban and rural areas, to evaluate the impacts of a practice on urban and rural development.

These four sub-fields are from ISO (2010), Khan, Sadiq and Veitch (2004), Veleva, Hart, Greiner and Crumbley (2001), and Zhu, Sarkis and Lai (2007).

\subsection{Social fields and sub-fields}

Social responsibility is a global indicator used to assess a company's social performance. It assesses the social consequences of the company's activity for all its stakeholders, mainly its employees (working conditions, level of remuneration, discrimination), its suppliers, its customers (safety and psychological 
impacts of products), the local communities (nuisances, respect for cultures) and society in general. The analysis of the inventory of the social fields found in the recent literature (GRI, 2007; ISO, 2010; OECD, 2000) allows us to distinguish five social fields: work conditions, human rights, societal commitment, customer issues, and business practices.

Based on GRI (2007) and completed by Azapagic and Perdan, (2000), Carter and Jennings, (2002), Hutchins and Sutherland (2008), Krajnc and Glavic (2003, 2005), Matos (2007) and O'Connor and Spangenberg (2008), we present the field "Work conditions” through five sub-fields:

- Employment, to evaluate the impacts of a practice on employment in a company. In fact, as employers, companies contribute to achieving one of society's aims: to improve the standard of living, by providing both full and stable employment.

- Labor conditions, to evaluate the impacts of a practice on work conditions and social welfare in a company. This includes salaries and others compensations, working time, rest periods, vacations, disciplinary practices, and dismissals and maternity protection issues.

- Respect of social dialogue, to evaluate the impacts of a practice on social dialogue in a company. This includes all types of negotiation, consultation or information exchange between government representatives, employers and workers on general interest issues linked to economic and social issues.

- Health and security, to evaluate the impacts of a practice on employees' health and security. The aim is to promote and maintain the highest degree of physical, mental and social well-being in workers, and to prevent occupational accidents due to working conditions. It is also a question of workers' protection against health risks and the adaptation of the working environment to workers' physiological and psychological needs.

- Human resources development, to evaluate the impacts of a practice on the degree of human resources development in a company. The aim is to broaden individuals' choices by developing their capabilities and thus enabling them to be informed and to have a decent standard of living.

The second field, Human Rights, is composed of three sub-fields found in literature (Azapagic and Perdan, 2000; ISO 26000; Matos and Hall, 2007):

- Child and forced labor, to evaluate the impacts of a practice on hard labor and child labor (international labor standards generally set the minimum age for work at 15 and at 14 for certain developing countries).

- Freedom of association, to evaluate the impacts of a practice on workers' possibility of being represented. 
Doi: 10.1016/j.cie.2014.07.029

- Discrimination, to evaluate the impacts of a practice on non-discrimination, relating to sex, ethnic group, race or other. Income, working conditions and recruitment policies should be based on job requirements only.

Societal commitment has been more covered than the previous field (Hutchins \& Sutherland, 2008; Jung, Kim \& Rhee, 2001; Krajnc \& Glavic, 2005, Matos \& Hall, 2007; O'Connor \& Spangenberg, 2008;

OECD, 2000), and can be divided into five sub-fields:

- Involvement in local community, to evaluate the impacts of a practice on a company's outreach towards a community, in particular partnerships with local organizations and stakeholders.

- Education, culture and technological development, to evaluate the impacts of a practice on education, cultural activities and technological development of a community. Fundamental issues to develop social and economic dimensions.

- Job and wealth creation, to evaluate the impacts of a practice on job creation or deletion in a community and on the development of competences, which is a key component of job advancement.

- Healthcare, to evaluate the impacts of a practice on a community's healthcare.

- Societal investment, to evaluate the impacts of a practice on societal investment in a community.

Another significant field is "Customer issues”. Covered extensively in the literature (Kainuma \& Tawara, 2006; ISO, 2010; OECD, 2000; Veleva \& Ellenbecker, 2001), this field can be presented in four subfields:

- Marketing and information, to evaluate the impacts of a practice on information given to consumers.

- Healthcare and security, to evaluate the impacts of a practice on consumers' healthcare and security.

- Protection of private life, to evaluate the impacts of a practice on the protection of customers' data and privacy.

- Access to essential services, to evaluate the impacts of a practice on access to essential services like electricity, gas, water and phone.

The last social field is business practices. This field has been analyzed by Azapagic and Perdan (2000), Castka and Balzarova (2008), IS0 (2010), Labuschagne and Brent (2006), Matos and Hall (2007) and OECD, 2000. To cover this field, we suggest three sub-fields:

- Fight against corruption. 
Doi: 10.1016/j.cie.2014.07.029

- Fair-trading, to evaluate the impacts of a practice on competitive practices, given that free competition means that the economic actors are free to offer goods and services on the market and to choose their suppliers of goods and services.

- Promotion of corporate social responsibility in the sphere of influence. A firm can influence other firms by making procurement and purchasing decisions or, more broadly, decisions concerning the management of the logistic chain.

In this article we have cited the most significant references. A more extensive literature review in Chardine-Baumann (2011) provides a complete analysis that can be used for a detailed classification of all the issues, depending on the number and diversity of existing studies.

--- Insert Table 1 here ---

\section{An analytical model for assessment of SCM practice sustainable performance}

We propose a 3-level analytical assessment model for sustainable performance, applicable to all SCM practices (see Figure 2).

--- Insert Figure 2 here ---

As the extent to which a company implements a practice can vary widely, from very slight to full implementation, the significance of its impact cannot be taken into account in the same way in all cases. In order to consider this difference, we weight the impacts of SCM practices according to a degree of maturity which represents the degree of implementation of the SCM practice $\mathrm{W}\left(\mathrm{P}_{k}\right)$ (see Figure 2). We propose to characterize the maturity of a practice in terms of two properties: stability and scope.

- The stability of the implementation of a practice indicates the regularity of its implementation by the company; it can be occasional (according to the opportunities) or systematic.

- The scope of the implementation of a practice indicates the perimeter over which it extends. It can concern only some products/services or all the products/services.

The four degrees of maturity are broken down as follows (see Figure 3):

Degree 0: The practice is implemented to a small extent or not at all. Consequently, its implementation will not impact the fields in any significant way.

Degree 1: This practice is deployed occasionally for some products/services of the supply chain.

Degree 2: The company sets up this practice systematically for a selection of products/services of the supply chain or occasionally for all the products/services. 
Doi: 10.1016/j.cie.2014.07.029

Degree 3: The company sets up this practice systematically for all products/services.

--- Insert Figure 3 here ---

Our three-level analytical model for assessing the sustainable performance of SCM practices aggregates the sub-fields into three sustainable indexes. The concept of a composite index is a new approach which is well-suited to estimating the application of sustainable development in the socioeconomic sphere (Singh, Murty, Gupta \& Dikshit, 2007). It enables the conversion of the multiple available data in companies into terms corresponding to economic, environmental or social improvements. These indexes are increasingly recognized as appropriate tools for changes of strategy and for communication. By visualizing the phenomena and underlining trends, the sustainable indexes simplify, quantify, analyze and communicate information which would be otherwise be complex and complicated to interpret (Singh, Murty \& Dikshit, 2009).

The structure of these three indexes is presented in Figure 4. The method for calculating

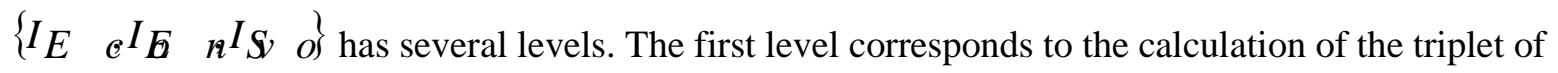
indexes bound to three dimensions of sustainable performance. The second level consists in estimating the performance of the various fields for every dimension. Finally, the third level of the model consists in evaluating the practices' impacts on the sub-fields.

\section{--- Insert Figure 4 here ---}

The third level is the assessment of practices' impacts on sub-fields.

The main problem of aggregating indicators into a composite index is the fact that indicators may be expressed in different units (Krajnc \& Glavic, 2005). To get around this difficulty and after having consulted several logistic managers, we propose to assess the impacts of each practice $\left(\mathrm{P}_{k}\right)$ in terms of three values:

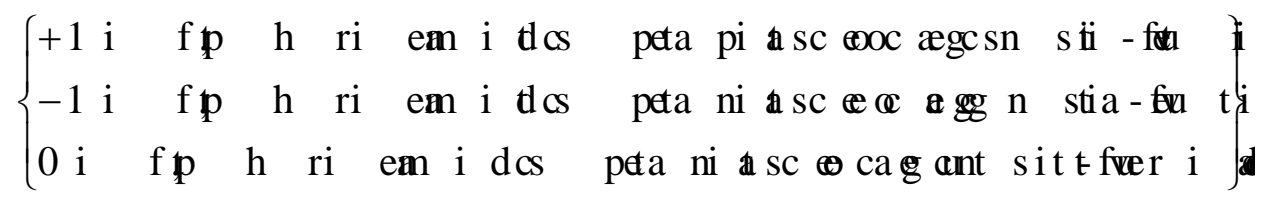

Let $S S-E C O_{i, j}$ denote the $j^{\text {th }}$ sub-field of the $i^{\text {th }}$ field of the economic dimension. SS-Env $v_{i, j}$ and $S S-S o c_{i, j}$ are defined similarly for the environmental and social dimensions.

$$
\operatorname{Impact}\left(\mathrm{P}_{k}, S S-E C O_{i, j}\right) \in\{-1,0,1\} \forall k \quad i=\text { fields } \quad i \text { from } 1 \text { to } 5
$$


Doi: 10.1016/j.cie.2014.07.029

$$
\begin{aligned}
& j=\text { sub-fields of } i \quad j \text { from } 1 \text { to } N\left(E_{C O}\right) \\
& \begin{array}{lll}
\operatorname{Impact}\left(P_{k}, S S-E n v_{i, j}\right) \in\{-1,0,1\} \forall k & i \text { fields } & i \text { from } 1 \text { to } 5 \\
& j=\text { sub-fields of } i & j \text { from } 1 \text { to } N\left(E c o_{i}\right)
\end{array} \\
& \operatorname{Impact}\left(P_{k}, S S-S_{0} c_{i, j}\right) \in\{-1,0,1\} \forall k \quad i=\text { fields } \quad i \text { from } 1 \text { to } 5 \\
& j=\text { sub-fields of } i \quad j \text { from } 1 \text { to } N\left(E c O_{i}\right)
\end{aligned}
$$

These impacts correspond to the relationships between a supply chain management practice and the sustainable fields. In order to take into account the level of implementation of SCM practices in a company, we propose to evaluate weighted impacts of each practice in terms of three values:

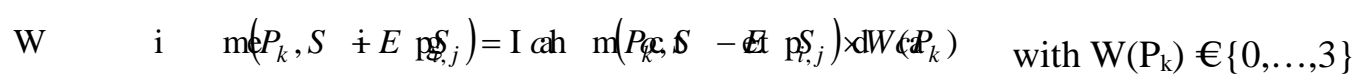

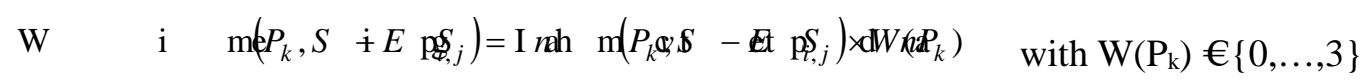

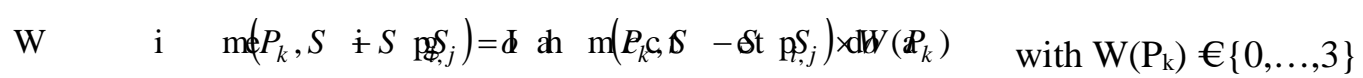

The second level corresponds to the evaluation of the different fields' performance for each dimension. We evaluate the performance of a practice in a field by the average of its impacts on the sub-fields. At this level, compensations between sub-fields are possible. For example, a SCM practice which improves the percentage of renewable energy but reduces the percentage of recyclable outputs has a neutral impact on the "Resources” field.

We define ${ }^{I}\left(P_{k}, E c q\right)$ the measure of the impact of practice $P_{k}$ on the $i^{\text {th }}$ economic field $E c O_{i}$ as:

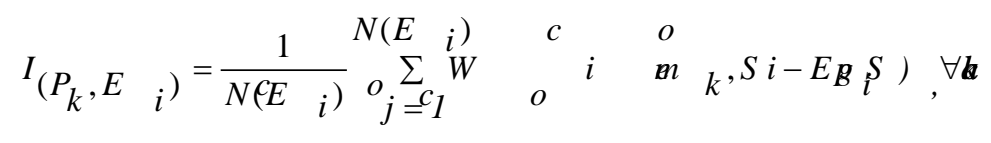

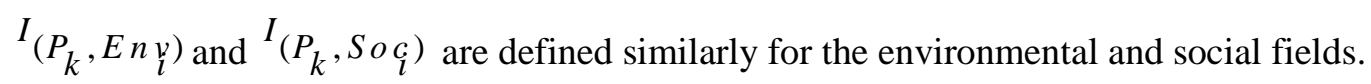

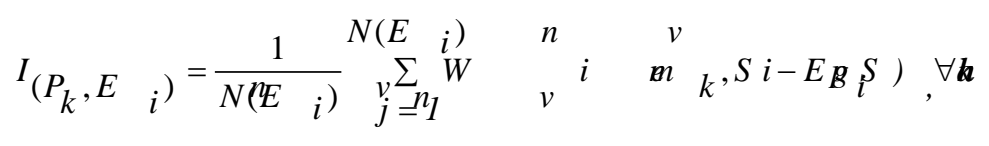

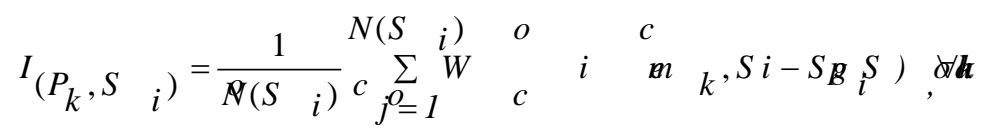

Finally, the first level of the model is the calculation of the triad of indices related to the three dimensions of sustainable performance. 
Doi: 10.1016/j.cie.2014.07.029

Each dimension - Economic, Environmental and Social - is composed of five fields. At this level, compensations between fields are allowed because we propose to sum the impacts of the fields. By cons, no compensation is permitted between dimensions.

We assess sustainable indices for a practice $\mathrm{P}_{k}$, by respectively $\mathrm{I}_{E c o}\left(P_{k}\right), \mathrm{I}_{E n v}\left(P_{k}\right)$, and $\mathrm{I}_{\text {soc }}\left(P_{k}\right)$, as:

$$
\begin{aligned}
& I_{E} \quad\left(\mathrm{k}^{\mathbb{P}}=_{O} \sum_{i=1}^{5} I_{\left(P_{k}, E \quad i\right)} \quad \forall b\right. \\
& I_{E} \quad\left(\mathbf{h}^{\mathbb{P}}={ }_{i=1}^{5} \sum_{i=1}^{5} I_{k}, E \quad i\right) n \forall k
\end{aligned}
$$

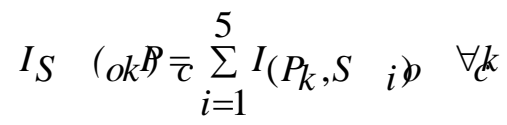

For each SCM practice, the sustainable performance is represented by a triad, which is made up of the economic, environmental and social performances: $\left\{\begin{array}{llll}I_{E} & \left(P_{\mathbb{k}}\right), b E & \left(P_{k}\right), I_{\$} & \left(B_{k}\right)\end{array}\right\}$.

\section{Illustration}

The assessment model has been applied to twenty-six best SCM practices (Chardine-Baumann, 2011). In this section we focus on two specific SCM practices that have been identified as the two most representative practices (SCC, 2008; Seuring, 2004; Shah and Ward, 2007; Tsoulfas and Pappis, 2006; Vachon and Klassen, 2008):

- "I am sharing with my upstream and/or downstream partners knowledge or ideas around the design of a new product to pool our competences” (P1)

- "I build and develop relations with my customers to include them better to adapt and personalize my products/services” (P2).

Based on a significant review of the scientific literature (Chardine-Baumann, 2011), we have analyzed 50 contributions to detect one or more relationships between the two selected SCM practices and sustainable fields. We have analyzed the results of these two practices on the sustainable sub-fields and fields according to our analytical assessment model (See Table 2). For P1, forty-seven sub-fields have been assessed out of a total of sixty-six sub-fields. So, P1 obtains a rate of response of $71 \%$, and P2 a rate of response of $82 \%$.

- The third level:

Concerning the economic dimension, $\mathrm{P}_{1}$ improves twenty-one sub-fields and deteriorates only two: “production responsiveness” and "delivery cost”. Only three sub-fields are not filled. P2 improves all the 
Doi: 10.1016/j.cie.2014.07.029

filled sub-fields and only three are not filled. Concerning the social dimension, $\mathrm{P}_{1}$ deteriorates four subfields and improves seven, and nine sub-fields are not filled. P2 deteriorates only one sub-field, “corruption”, and improves 10, while nine sub-fields are not filled.

We propose to focus the analysis on the environmental dimension. Table 2a presents the impacts of the two practices on the environmental sub-fields. On the environmental dimension, practice P2 has been filled out more than P1. This schema allows us to identify that P1 damages three environmental sub-fields $\left(\operatorname{Env}_{1,3} ; E_{n, 1}\right.$ et $\left.E_{3,4}\right)$ and improves seven other sub-fields. On the other hand, P2 has significant positive impacts on the sub-fields that have been filled out.

- The second level:

Among the fifteen fields, eleven have been filled out for P1 and ten for P2. Table 2b shows that even if P1 has positive impacts on economic and environmental dimensions, it also has negative impacts. Its sustainability must be studied with attention. Table 2b also shows that P2 is an economic and environmental best practice and has no impact on the social dimension.

- The first level:

Table 2c presents results as a triad. For P1, the triad is $\{0 ; 0 ; 1\}$ and for $\mathrm{P} 2\{1 ; 5 ; 0\}$. We notice that the values of aggregated impacts of the two practices are positive. Moreover, P2 obtains the best environmental result, which is 5 . We notice that P1 has a neutral aggregated impact on economic and environmental dimensions. The second level allows us to underline the impacts of some fields, which are compensated at the aggregated first level.

Because these two practices do not create significant negative impacts, we consider that they are two best sustainable practices.

--- Insert Table 2 here ---

Finally, the use of the proposed analytical model on the three-dimensional framework allows practitioners to qualify SCM practices known as best not only from the economic point of view, but also from the environmental and social points of view.

\section{Conclusion}

In this paper we have presented a framework to characterize the sustainable performance of a company in terms of the impacts of its SCM practices, and a model to assess its sustainable performance homogeneously. This contribution answers the initial question of how to assess the sustainable 
Doi: 10.1016/j.cie.2014.07.029

performance of SCM practices. The framework is based on the identification of a sustainable fields set potentially impacted by the implementation of SCM practices. These fields reflect the three dimensions of sustainable development through: reliability, responsiveness, flexibility, financial performance, quality, environmental management, use of resources, pollution, dangerousness, protection of natural environment, work conditions, human rights, societal commitment, consumer issues and business practices. To identify, estimate and aggregate the relationships between supply chain management practices and their impact on performance, we have proposed a framework for sustainable performance characterization and an analytical model for sustainable performance assessment. The framework is used to characterize a firm's sustainable performance in the economic, environmental and social fields. The analytical assessment model, based on the concept of a composite index, corresponds perfectly to the sustainable development triptych, identified by the triad: $\left\{I_{E} c, b E n, b_{S} o\right\}_{c}$.

Applying the framework to the study of two known practices, considered as "best" from the economic point of view, we have characterized these practices from the perspective of the other two dimensions of sustainable development. This has enabled us to verify whether a best economic practice is also a best sustainable practice. This model can easily be applied to any SCM practice that is considered as a best practice at a given time in a company, or that a company intends to implement.

The proposed framework can also be applied by a company in order to highlight those SCM practices that impact its sustainable performance more positively, depending on its objectives. The use of multi-criteria approaches on the framework could enable one to choose the most suitable SCM practices to be used in a given context, or to classify SCM practices according to companies’ contexts and objectives.

\section{Acknowledgements}

This work has been carried out as part of the French research project COPILOTES 2 supported by the Rhône-Alpes Region (France). The authors would like to thank the anonymous referees for their valuable suggestions, and Liz Libbrecht for proof-reading this article.

\section{References}

Azapagic, A. \& Perdan, S. (2000). Indicators of sustainable development for industry a general framework. Process Safety and Environmental Protection, 78(4), 243-261.

Barbiroli, G. \& Raggi, A. (2003). A method for evaluating the overall technical and economic performance of environmental innovations in production cycles. Journal of Cleaner Production, 11(4), 365-374. 
Doi: 10.1016/j.cie.2014.07.029

Carroll, A.B. (1979). A Three-Dimensional Conceptual Model of Corporate Performance. Academy of Management Review, 4(4), 497-505.

Carter, C.R. \& Jennings, M. M. (2002). Logistics social responsibility: An integrative framework. Journal of Business Logistics, 23(1), 145-178.

Castka, P. \& Balzarova, M. (2008). ISO 26000 and supply chains-On the diffusion of the social responsibility standard. International Journal of Production Economics, 111(2), 274-286.

Chardine-Baumann, E. (2011). Models for assessing economic, environmental and social performances in supply chains. PhD thesis, Institut National des Sciences Appliquées (INSA) de Lyon.

Clarkson M. (1995). A Stakeholder Framework for Analyzing and Evaluating Corporate Social Performance. Academy of Management Review, 20, 42-56.

Cooper M., Lambert D. \& Pagh J. (1997). Supply chain management: more than a new name for logistics. International Journal of Logistics Management. 8(1), 1-14.

Côté R., Lopez J., Marche S., Perron G. \& Wright R. (2008). Influences, practices and opportunities for environmental supply chain management in Nova Scotia SMEs. Journal of Cleaner Production, 16(15), 1561-1570.

Cruz J. M. \& Wakolbinger T. (2008). Multiperiod effects of corporate social responsibility on supply chain networks, transaction costs, emissions, and risk. International Journal of Production Economics, 116(1), 61-74.

Darnall, N., Jolley, J. \& Handfield, R. (2006). Environmental management systems and green supply chain management: Complements for sustainability? Business Strategy and the Environment, 17, 30-45.

De Benedetto, L. \& Klemes, J. (2009). The Environmental Performance Strategy Map: an integrated LCA approach to support the strategic decision-making process. Journal of Cleaner Production, 17(10), 900906.

ECR (2008). The road map.Efficient consumer response. Available on: < http://www.ecr-all.org/ >

European Commission (2009). EMAS - The European Eco-Management and Audit Scheme, European Union, Belgium. Available on: < http://ec.europa.eu/environment/emas/index_en.htm >

Farooq, O., Farooq, M. \& Reynaud E. (2009). Reaping the rewards of doing good: Effects of CSR on work related attitudes and behaviors. In: 8th CSR conference of Social responsibility research network, Cape Town, South Africa.

Ferretti I., Zanoni S., Zavanella L. \& Diana A. (2007). Greening the aluminum supply chain. International Journal of Production Economics,108(1-2), 236-245.

Galia (2007). Evalog: Global Evalog frame of reference. Available on:

$<$ http://www.odette.org/html/home.htm >

Gauthier, C. (2005). Measuring corporate social and environmental performance: the extended life-cycle assessment. Journal of Business Ethics, 59(1-2), 199-206. 
Doi: 10.1016/j.cie.2014.07.029

GRI (2007). Sustainability Reporting Guidelines (G3). The Netherlands: Global Reporting Initiative.

Gunasekaran, A., Patel, C. \& Tirtiroglu, E. (2001). Performance measures and metrics in a supply chain environment. International Journal of operations \& Production Management, 21(1), 71-87.

Hutchins, M.J \& Sutherland, J.W. (2008). An exploration of measures of social sustainability and their application to supply chain decisions. Journal of Cleaner Production, 16(15), 1688-1698.

ISO (2010). ISO 26000: Guidance on social responsibility. International Organization for Standardization.

Jash C. (2000). Environmental performance evaluation and indicators. Journal of Cleaner Production, 8(1), 79-88.

Jung E., Kim J. \& Rhee S. (2001). The measurement of corporate environmental performance and its application to the analysis of efficiency in oil industry. Journal of Cleaner Production, 9(6), 551-563.

Kainuma, Y. \& Tawara, N. (2006). A multiple attribute utility theory approach to lean and green supply chain management. International Journal of Production Economics, 10(1), 99-108.

Khan, F., Sadiq, R. \& Veitch, B. (2004). Life cycle iNdeX (LInX): a new indexing procedure for process and product design and decision-making. Journal of Cleaner Production, 12(1), 59-76.

Krajnc D. \& Glavic P. (2003). Indicators of sustainable production. Clean Technologies and Environmental Policy. 5(3-4), 279-288.

Krajnc D. \& Glavic P. (2005). A model for integrated assessment of sustainable development. Resources, Conservation and Recycling, 43(2), 189-208.

Labuschagne, C. \& Brent, A.C. (2006). Social indicators for sustainable project and technology life cycle management in the process industry. The International Journal of Life Cycle Assessment, 11(1).

Lynch, R. \& Cross, K. (1991). Measure Up - the essential guide to measuring business performance. London: Mandarin.

Lambert S., Riopel D. \& Abdul-Kader W. (2011). A reverse logistics decisions conceptual framework. Computers \& Industrial Engineering, 61(3), 561-581.

Maire J., Bronet V. \& Pillet M. (2005). A typology of "best practices” for a benchmarking process. Benchmarking: An International Journal, 12(1), 45-60.

Matos, S. \& Hall, J. (2007). Integrating sustainable development in the supply chain: The case of life cycle assessment in oil and gas and agricultural biotechnology. Journal of Operations Management, 25(6), 1083-1102.

Michelsen, O., Magerholm Fet, A. \& Dahlsrud, A. (2006). Eco-efficiency in extended supply chains: A case study of furniture production. Journal of Environmental Management, 79(3), 290-297.

Noci, G. (1997). Designing green vendor rating systems for the assessment of a supplier's environmental performance. European Journal of Purchasing \& Supply Management, 3(2), 103-114.

OECD (2000). Text of the OECD Guidelines for Multinational Enterprises. Paris: Organization for 
Doi: 10.1016/j.cie.2014.07.029

Economic Co-operation and Development. Available at:

http://www.oecd.org/dataoecd/56/36/1922428.pdf

Oliver Wight International Inc (2005). The Oliver Wight Class A Checklist For Business Excellence, Sixth edition. John Wiley \& Sons Inc.

Perrin A. (2006). Managing organizational practices transfer across boundaries and culture. In: Academy of Management Annual Meeting, Atlanta, GA, USA.

Rao, P., O'Castillo, O., Intal Jr, P. S., Sajid, A. (2006). Environmental indicators for small and medium enterprises in the philippines an empirical research. Journal of Cleaner Production, 14(5), 505-515.

Roy, B. (1996). Multicriteria Methodology for Decision Aiding. Springer.

Rubio S. \& Corominas A. (2008). Optimal manufacturing-remanufacturing policies in a lean production environment. Computers \& Industrial Engineering, 55(1), 234-242.

SAI (2008). SA8000: Social Accountability International. New-York. Available on: < http://www.saintl.org/index.cfm?fuseaction=Page.viewPage\&pageId=937\&parentID=479\&nodeID=1 >

Sawadogo M. \& Anciaux D. (2010). Reducing the environmental impacts of intermodal transportation: a multi-criteria analysis based on ELECTRE and AHP methods. In: Information Systems, Logistics and Supply Chain Conference, Casablanca, Morocco.

SCC (2000). Supply Chain Operations Reference Model. Cypress, Texas, USA: Supply Chain Council.

SCC (2008). Supply Chain Operations Reference Model. Cypress, Texas, USA: Supply Chain Council. Available on: < http://supply-chain.org/ >

Seuring S. (2004). Integrated chain management and supply chain management comparative analysis and illustrative cases. Journal of Cleaner Production, 12(8-10), 1059-1071.

Shah R. \& Ward P. (2007). Defining and developing measures of lean production. Journal of Operations Management, 25(4), 785-805.

Singh R. K., Murty H. \& Dikshit A. (200)9. An overview of sustainability assessment methodologies. Ecological Indicators, 9(2), 189-212.

Singh R. K., Murty H., Gupta S. \& Dikshit A. (2007). Development of composite sustainability performance index for steel industry. Ecological Indicators, 7(3), 565-588.

Siracusa G., La Rosa A. \& Sterlini S. (2004). A new methodology to calculate the environmental protection index (Ep): A case study applied to a company producing composite materials. Journal of Environmental Management, 73(4), 275-284.

Tam, C.M., Tam, V.W. \& Tsui, W.S. (2004). Green construction assessment for environmental management in the construction industry of Hong Kong. International Journal of Project Management, 22(7), 563-571.

Tseng M., Divinagracia L. \& Divinagracia R. (2009). Evaluating firm’s sustainable production indicators in uncertainty. Computers \& Industrial Engineering, 57(4), 1393-1403. 
Tsoulfas G. T. \& Pappis C. P. (2006). Environmental principles applicable to supply chains design and operation. Journal of Cleaner Production, 14(18), 1593-1602.

United Nations Environment Program (2000). Global Compact. United Nations.

Vachon S. \& Klassen R. (2008). Environmental management and manufacturing performance: The role of collaboration in the supply chain. International Journal of Production Economics, 111(2), 299-315.

Veleva V., Hart M., Greiner T. \& Crumbley C. (2001). Indicators of sustainable production. Journal of Cleaner Production, 9(5), 447-452.

Warhurst, A. (2002). Sustainability Indicators and Sustainability Performance Management. United Kingdom: World Business Council for Sustainable Development.

WCED (1987). Our Common Future. Oxford, United Kingdom: Oxford University Press.

Wood D. A. (1991). Corporate Social Performance Revisited. Academy of Management Review, 16(4), 691-718.

Zhou Z., Cheng S. \& Hua B. (2000). Supply chain optimization of continuous process industries with sustainability considerations. Computers \& Chemical Engineering, 24(2-7), 1151-1158.

Zhu, Q. \& Sarkis, J. (2004). Relationships between operational practices and performance among early adopters of green supply chain management practices in Chinese manufacturing enterprises. Journal of Operations Management, 22(3), 265-289.

Zhu, Q., Sarkis, J. \& Lai, K. (2007). Initiatives and outcomes of green supply chain management implementation by chinese manufacturers. Journal of Environmental Management, 85(1), 179-189.

\begin{tabular}{|c|c|c|l|}
\hline Dimensions & Fields & $\begin{array}{c}\text { Number of } \\
\text { sub-fields }\end{array}$ & \multicolumn{1}{|c|}{ Sub-fields } \\
\hline Economic & $\begin{array}{c}\text { Reliability } \\
\text { (Eco1) }\end{array}$ & 4 & $\begin{array}{l}\text { customer service, suppliers' service, reliability } \\
\text { of stocks, reliability of forecasts }\end{array}$ \\
\cline { 2 - 4 } & $\begin{array}{c}\text { Responsiveness } \\
\text { (Eco2) }\end{array}$ & 8 & $\begin{array}{l}\text { design responsiveness, purchase } \\
\text { responsiveness, source responsiveness, } \\
\text { production responsiveness, delivery } \\
\text { responsiveness, sell responsiveness, return } \\
\text { responsiveness, supply chain responsiveness }\end{array}$ \\
\cline { 2 - 4 } & $\begin{array}{c}\text { Flexibility } \\
\text { (Eco3) }\end{array}$ & 4 & $\begin{array}{l}\text { suppliers flexibility, supply flexibility, } \\
\text { production flexibility, delivery flexibility }\end{array}$ \\
\cline { 2 - 4 } & $\begin{array}{c}\text { Financial } \\
\text { performance } \\
\text { (Eco4) }\end{array}$ & 7 & $\begin{array}{l}\text { design cost, purchase cost, source cost, } \\
\text { production cost, delivery cost, return cost, } \\
\text { supply chain cost }\end{array}$ \\
\hline (Eco5) & 3 & $\begin{array}{l}\text { product/service quality, quality performance of } \\
\text { suppliers, production quality }\end{array}$ \\
\hline
\end{tabular}


Doi: 10.1016/j.cie.2014.07.029

\begin{tabular}{|c|c|c|c|}
\hline Dimensions & Fields & $\begin{array}{l}\text { Number of } \\
\text { sub-fields }\end{array}$ & Sub-fields \\
\hline \multirow[t]{5}{*}{ Environmental } & $\begin{array}{l}\text { Environmental } \\
\text { management } \\
(\text { Env1) }\end{array}$ & 4 & $\begin{array}{l}\text { environmental budget, environmental } \\
\text { certification, environmental compliance, } \\
\text { workers implications }\end{array}$ \\
\hline & $\begin{array}{l}\text { Use of resources } \\
\text { (Env2) }\end{array}$ & 5 & $\begin{array}{l}\text { renewable energy, recycled water, inputs } \\
\text { stemming from the recycling, recyclable } \\
\text { outputs, recyclable wastes }\end{array}$ \\
\hline & $\begin{array}{l}\text { Pollution } \\
\text { (Env3) }\end{array}$ & 4 & $\begin{array}{l}\text { air pollution, water pollution, land pollution, } \\
\text { other pollution }\end{array}$ \\
\hline & $\begin{array}{l}\text { Dangerousness } \\
\text { (Env4) }\end{array}$ & 3 & $\begin{array}{l}\text { dangerous inputs, dangerous outputs, } \\
\text { dangerous wastes }\end{array}$ \\
\hline & $\begin{array}{l}\text { Natural } \\
\text { environment } \\
\text { (Env5) }\end{array}$ & 4 & $\begin{array}{l}\text { eco-systemic services, respect of biodiversity, } \\
\text { land use, development of urban and rural areas }\end{array}$ \\
\hline \multirow[t]{5}{*}{ Social } & $\begin{array}{l}\text { Work conditions } \\
\text { (Soc1) }\end{array}$ & 5 & $\begin{array}{l}\text { employment, work conditions, respect of social } \\
\text { dialogue, health and security, human resources } \\
\text { development }\end{array}$ \\
\hline & $\begin{array}{l}\text { Human rights } \\
\text { (Soc2) }\end{array}$ & 3 & $\begin{array}{l}\text { child and forced labor, freedom of association, } \\
\text { discrimination }\end{array}$ \\
\hline & $\begin{array}{l}\text { Societal } \\
\text { commitment } \\
\text { (Soc3) }\end{array}$ & 5 & $\begin{array}{l}\text { involvement in local community, education, } \\
\text { culture and technological development, job } \\
\text { creation, healthcare, societal investment }\end{array}$ \\
\hline & $\begin{array}{l}\text { Customers issues } \\
\text { (Soc4) }\end{array}$ & 4 & $\begin{array}{l}\text { marketing and information, healthcare and } \\
\text { security, protection of private life, access to } \\
\text { essential services }\end{array}$ \\
\hline & $\begin{array}{l}\text { Business practices } \\
\text { (Soc5) }\end{array}$ & 3 & $\begin{array}{l}\text { fight against corruption, fair-trading, } \\
\text { promotion of corporate social responsibility in } \\
\text { the sphere of influence }\end{array}$ \\
\hline
\end{tabular}

Table 1: Model characterizing sustainable performance

\begin{tabular}{|l|l|l|l|l|}
\hline (a) & P1 & \\
& &
\end{tabular}


Doi: 10.1016/j.cie.2014.07.029

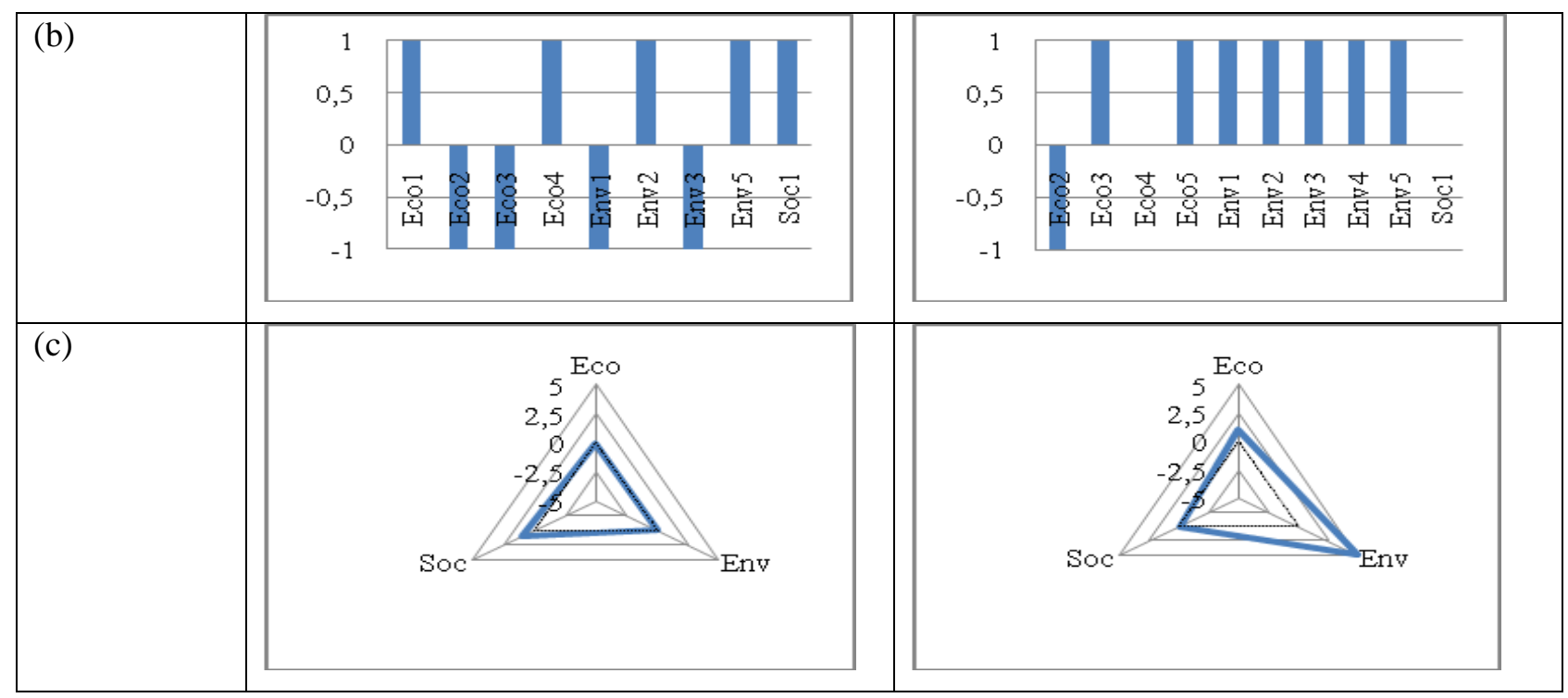

Table 2: Results of analytical assessment model for practices P1 and P2 